\title{
Alternative approach to analysis of risks affecting the efficiency of implementing the investment project in the conditions of global instability of economic space
}

\author{
Liana M. Chechenova ${ }^{I}$, Natalia V. Volykhina ${ }^{2 *}$, and Yuriy V. Egorov ${ }^{3}$ \\ ${ }^{1}$ Emperor Alexander I Petersburg State Transport University, Russia \\ ${ }^{2}$ Emperor Alexander I Petersburg State Transport University, Russia \\ ${ }^{3}$ Emperor Alexander I Petersburg State Transport University, Russia
}

\begin{abstract}
This article is devoted to the study of improving the use of expert assessments for risk analysis, affecting the effectiveness of the implementation of a comprehensive investment project in the global instability of the economic space. The existing methods of expert assessments and Monte-Carlo simulation methods used to identify and assess the risks of investment projects are described. A systematic analysis of the main risks of investment projects in the context of globalization and risk management methods was carried out. The author's classification of risks of investment projects using the criteria of economic efficiency has been developed. An approach to risk analysis, affecting the effectiveness of the implementation of complex investment projects based on existing methods using the concept of the "reduced" random factor, is proposed. This approach is used to analyse project implementation risks in the conditions of market instability with the development of recommendations for managing the main project risks. The author's risk classification of investment projects is important at the stage of analysing risks arising from the study of sales markets, as well as during the management decisionmaking process, which minimizes the possible adverse impact on an organization, including losses caused by random events. The proposed approach can be applied to the analysis, express-analysis and risk management of long-term complex investment projects in the conditions of global instability of the economic space.
\end{abstract}

\section{Introduction}

In the field of investment projects' risk management for any organization, it is necessary to develop an integrated, comprehensive approach to risk management. Among Russian scientists, this direction has recently been reflected in the studies of P. Vilensky, V. Livshits, S. Smolyak [1], I. Balabanov [2], A. Damodaran [3], E. Kuzmin [4], A. Lobanov [5], T. Nikitin [6], V. Repin [7], E. Severnyuk [8], O. Gizatullina, V. Piskunov, T. Tarasova [9]. Among foreign authors can be identified N. GM. [10] Hillson D. [11], S. Angilella, S. Mazzu

*Corresponding author: natalyabatalova@yandex.ru 
[12], H. Mejdoub, M. Ben Arab [13], CV. Silva, ATN. Batista, HL. Sales, RS. da Penha [14], E. Delage, D. Kuhn, W. Wiesemann [15], N. Petrusheva [16], T. Bozaykut-Buk [17], MA. Andor, C. Parmeter, S. Sommer [18], MG. Scudder, J. Herbohn, J. Baynes [20], T. Kliestik et al. [20], M. Hudáková, J. Dvorský [21], K. Valaskova et al. [22], and other authors, which highlight issues of risk management[23-25], assessment [26], the impact of risks on the value of investment projects [27-30].

The priority areas of risk analysis in the implementation of an investment project are: determining the probability of occurrence of a risk, qualitative identification of risks, determining the size of probable losses, taking into account risks, developing risk mitigation.

However, at present, there is no complete and justified theoretical and practical base regarding methodological recommendations for assessing the value of investment projects at different stages of the life cycle under conditions of uncertainty and risk. At the same time, determining the probability of occurrence of risks and possible losses continues to be a serious problem for complex investment projects with a long implementation period.

In this paper, we presented one of the approaches to risk analysis that affect the effectiveness of the implementation of a complex investment project. This approach is considered by the example of identifying and assessing risks that affect the effectiveness of an investment project to create a multi-brand dealer auto center, implemented by EurosibAutoUK JSC in 2018-2024. The main feature of the proposed approach is the joint use of the expert assessment method and the Monte Carlo simulation method.

\section{Methodology: identification and assessment of risks affecting the effectiveness of the investment project}

The modern risk management process of a comprehensive investment project requiring a long implementation period is complex and multi-stage. To achieve maximum economic efficiency of the implementation of the investment project at the initial (first) stage of the analysis, it is necessary to apply qualitative methods to identify all types of risks that threaten the investment project, as well as to identify possible loss of resources that accompany the onset of risk events.

To identify the risks of the investment project on the creation of a multi-brand dealer auto center of Eurosib-Auto UK JSC, we used a high-quality method of expert assessments. When using the method of expert evaluations, specialists and managers of the automotive industry of St. Petersburg were asked to answer the questionnaire in order to identify and assess risks that affect the effectiveness of the project of Eurosib-Auto UK JSC. During the questionnaire, experts ranked the probability of occurrence of possible risks, using ranks from 1 (least significant) to 10th (most significant). After processing the received questionnaire data for each indicator, the total sums of ranks are calculated (taking into account the opinions of all experts) using formula 1 :

$$
R_{i}=\sum_{j=1}^{N} r_{i j}
$$

For the transition from rank estimates $\mathrm{r} 1, \mathrm{r} 2 \ldots \mathrm{rn}$ to weights, various formulas can be used, we used the Fishborn formula.

At the next (second) stage of risk analysis of the investment project, it is proposed to use quantitative methods for analyzing the investment project, in particular, simulation methods. The Monte Carlo method is the most common of the simulation methods. In the framework of this method, the analysis of the impact of identified risks of investment projects is carried out using models of possible results [23].

In this paper, we applied a model of possible results using data from an investment project implemented by Eurosib-Auto UK JSC. The predicted indicators used in the calculation 
include the most significant risks identified earlier using a qualitative method of expert assessments:

- decrease in sales of new cars;

- change in the exchange rate;

- change (increase) in the payback period of an investment project.

Note that the Monte Carlo method, although it refers to quantitative methods of analysis, can use elements of a qualitative method of expert assessments in constructing an optimistic, pessimistic, and realistic scenario for changing random indicators. If the volume of car sales is predicted as random variables that do not depend on the company's strategy, then their probabilistic change should be included in the simulation model, the currency should also be included in the model, for this investment project - the US dollar, since the currency is not controlled by the company.

\section{Results and discussion}

Implementing the methodology explained in Chapter 2 of our paper produced the following results and discussion.

At the first stage of our analysis we identified main risks of the investment project. Table 1 shows the processed results of the expert survey and the calculated weighting factors using formula 1 and Fishborn formula.

Table 1. The results of expert risk assessments of the investment project

\begin{tabular}{|l|c|c|c|}
\hline \multicolumn{1}{|c|}{ Criterion } & $\mathrm{Ri}$ & Position $\left(\mathrm{r}_{\mathrm{i}}\right)$ & $\mathrm{a}_{\mathrm{i}}$ \\
\hline New car sales reducing & 38 & 7,6 & 0,19 \\
\hline Project payback periods increasing & 14 & 2,8 & 0,07 \\
\hline Project cost increasing & 29 & 6,0 & 0,15 \\
\hline Changes in exchange rates & 34 & 7,4 & 0,19 \\
\hline Underfunding of an investment project & 16 & 3,2 & 0,08 \\
\hline Failure to achieve the specified project criteria & 19 & 3,8 & 0,10 \\
\hline Counterparty default & 17 & 3,4 & 0,09 \\
\hline Limitation of cars supplying & 26 & 5,2 & 0,13 \\
\hline
\end{tabular}

Consistency of expert opinion can be assessed using a concordance coefficient. For the investment project under consideration, the concordance coefficient is 0.71 , which indicates a high degree of consistency of expert opinions. Thus, using the method of expert assessments, it was definitely determined that the probability of the occurrence of the risk situation of the investment project under consideration is average. It should also be taken into account that on the basis of an expert survey and mathematical processing of the data results, it can be concluded that the risks that received the highest score (greatest significance) in the assessment are:

- decrease in sales of new cars;

- change in the exchange rate;

- change (increase) in the payback period of an investment project.

Second stage of our analysis was assessment of the impact of identified risks of the investment project on economic efficiency of the project using models of possible results.

At the initial stage of the calculation, we formed a matrix that displays the forecast of car sales per year for 6 years in advance - table 2 . 
Table 2. Forecast of sales of new cars by years, pcs.

\begin{tabular}{|l|c|c|c|c|c|c|c|}
\hline Car model & $\mathbf{2 0 1 8}$ & $\mathbf{2 0 1 9}$ & $\mathbf{2 0 2 0}$ & $\mathbf{2 0 2 1}$ & $\mathbf{2 0 2 2}$ & $\mathbf{2 0 2 3}$ & $\mathbf{2 0 2 4}$ \\
\hline Opel & 342 & 514 & 497 & 547 & 547 & 547 & 547 \\
\hline Chevrolet & 1113 & 1671 & 1617 & 1778 & 1778 & 1778 & 1778 \\
\hline Saab & 17 & 30 & 33 & 36 & 36 & 36 & 36 \\
\hline Cadilac & 10 & 15 & 17 & 18 & 18 & 18 & 18 \\
\hline Daewoo & 300 & 489 & 490 & 517 & 620 & 744 & 744 \\
\hline TOTAL & 1782 & 2719 & 2654 & 2896 & 2999 & 3123 & 3123 \\
\hline
\end{tabular}

For the investment project under consideration, a forecast indicator of sales for 6 years was calculated and the probability of an optimistic, pessimistic and realistic scenario for the sales of new cars was estimated, the scenarios are presented in table 3 . To assess the likelihood of the scenarios, the expert estimates. Scenarios were generated by experts for the forecast volume of car sales, measured in conventional "reduced" cars independent of the car manufacturer, car make and year of sale (within the considered period of 6 years). This allowed us to simplify the analysis by moving from a random matrix to a single random indicator - the sales volume of "reduced" cars for 6 years.

Table 3. Estimation of sales for 6 years in three scenarios, pcs.

\begin{tabular}{|l|c|c|}
\hline $\begin{array}{c}\text { New car sales } \\
\text { scenario }\end{array}$ & $\begin{array}{c}\text { Sales volume of new cars, } \\
\text { pcs }\end{array}$ & $\begin{array}{c}\text { The probability of } \\
\text { implementation, } \%\end{array}$ \\
\hline Pessimistic & 11578 & 20 \\
\hline Realistic & 19296 & 70 \\
\hline Optimistic & 15437 & 10 \\
\hline
\end{tabular}

Using the obtained data, 30 iterations of simulation experiments were carried out (calculated) using the normal distribution, which allowed generating random numbers for further calculations of the net present value (NPV) of the project.

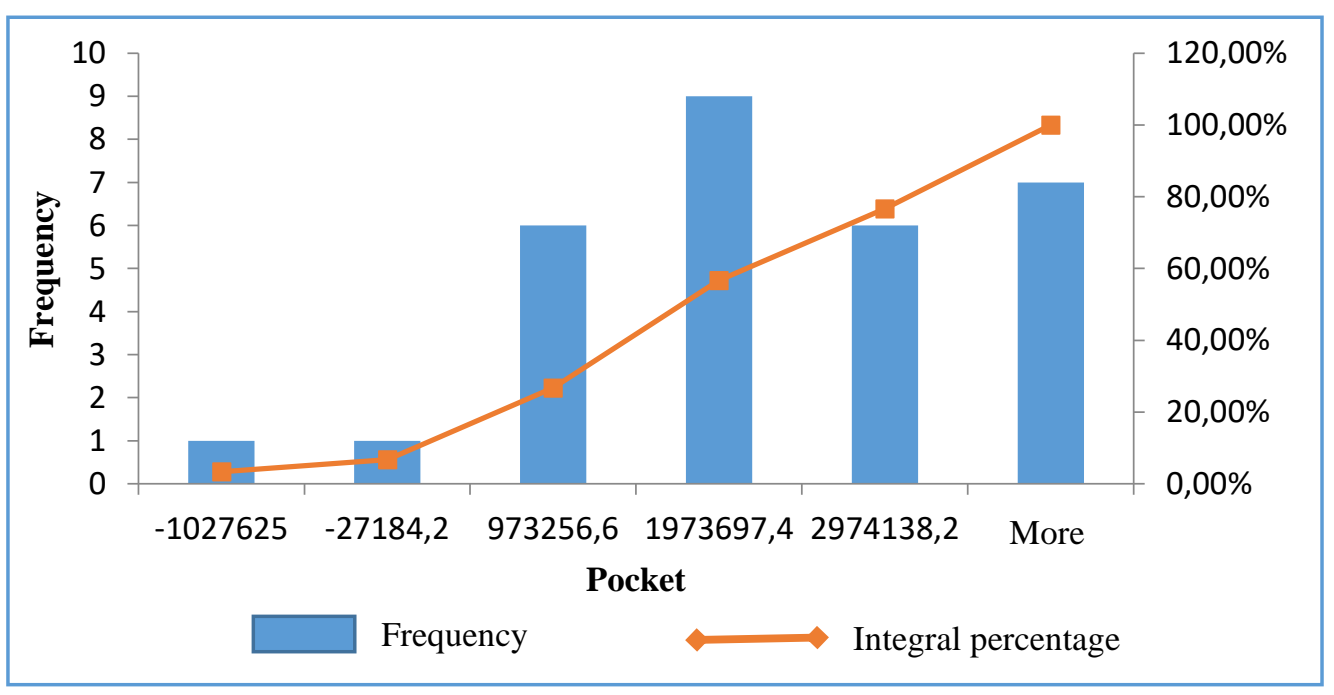

Fig. 1. Distribution density of new car sales

The result of processing the obtained calculation values of the simulation experiment model is a histogram of the distribution shown in Figure 1. The analysis results indicate that in $10 \%$ of cases NPV assumes a negative value due to fluctuations in sales; $36.6 \%$ of cases 
give the project NPV less than average. Similar calculations were performed for a quantitative analysis of the risk of changes (increase) in the payback period of an investment project and the risk of currency volatility. It was found that in $40 \%$ of cases, changes in sales volumes will lead to an increase in the payback period of the project relative to the average payback period (4.5 years). Also, in $56.67 \%$ of cases, a change in the US dollar gives an NPV value less than average. However, only in $3 \%$ of cases the fluctuation of the US dollar will lead to a negative NPV value of the project.

Thus, considering the possibility of the influence of the main risks on the effectiveness of the project, it was concluded that the main threat is the risk of lower sales. The risk of reducing project efficiency from changes in the exchange rate is low.

\section{Conclusion}

Our risk analysis of the investment project of the Eurosib-Auto UK company on the creation of a multi-brand dealer car sales center allowed us to identify and assess the main risks affecting the effectiveness of the ongoing investment project. Based on our analysis, we formulated recommendations on risk management of the investment project under consideration.

Our proposed approach to analyzing risks that affect the efficiency of a complex investment project based on a combination of the expert assessment method and the Monte Carlo method includes a qualitative analysis of identifying the main risks of the project and a quantitative assessment of the identified risks with the subsequent development of recommendations for managing project risks. The transition to the reduced units of measurement random factors (in terms of the use of forecast sales volumes) helped to simplify calculations in the proposed approach. This approach can be applied for analysis, rapid analysis and risk management of complex projects designed for a long implementation period.

\section{References}

1. P. Vilensky, V. Livshits, S. Smolyak, Assessment of Efficiency of Investment Projects: Theory and Practice. (Moscow, Pauly Print Service, 2015)

2. I. Balabanov, Risk management. (Moscow, Finance and Statistics, 2017)

3. A. Damodaran, Strategic risk-management. (Moscow, Williams, 2010)

4. E. Kuzmin, Conceptual approaches to risk management of complex organizational and economic systems: systematization and critical analysis. The Bulletin of SRSTU (NPI), 2, 2013.

5. A. Lobanov, A. Chugunov, Encyclopedia of Financial Risk Management. (Moscow, Alpina Business Books, 2009).

6. T. Nikitina, Commercial and financial risk insurance. (St. Petersburg, Piter, 2008).

7. V. Repin, Business processes. Modeling, implementation, management, (Moscow, Mann, Ivanov and Ferber, 2013).

8. E. Severnyuk, Risk management in the new coordinate system. Iss. of Risks Analyz., 11(2) (2014)

9. O. Gizatullina, V. Piskunov, T. Tarasova, Simulation modeling for effectiveness evaluation of investment in risk and uncertainty area. GCPMED 2018, 57, 567 (2019)

10. M. Ng, Int. J. of Proj. Manag., 25(1), 66 (2007) 
11. D. Hillson, D. Hulett, Assessing Risk Probability: Alternative Approaches. Part of PMI Glob. Congr. Proceed., 1 (2010)

12. S. Angilella, S. Mazzu, A credit risk model with an automatic override for innovative small and medium-sized enterprises J. of Oper. Res. Soc. (2017)

13. H. Mejdoub, M. Ben Arab, Insurance risk capital and risk aggregation: bivariate copula approach. Int. J. of Comput. Econ. And Economet., 9(3), 202 (2019)

14. CV. Silva, ATN. Batista, HL. Sales, RS. da Penha, Application of the Monte Carlo method in evaluation of the AMBEV company with unusual capital cost. Revista Eniac Pesquisa, (8)1, 153 (2019)

15. E. Delage, D. Kuhn, W. Wiesemann, "Dice"-sion-Making Under Uncertainty: When Can a Random Decision Reduce Risk? Manag. Sci., 65(7), 3282 (2019)

16. N. Petrusheva, Management of financial risks in international trade financing. Casopis Za Ekonomiju I Trzisne Komunikacije, 6(1), 81 (2016)

17. T. Bozaykut-Buk, Giving Risk Management Culture a Role in Strategic Planning. Risk Manag., Strat. Think. And Leadersh. In the Financ. Serv. Ind., 311 (2017)

18. MA. Andor, C. Parmeter, S. Sommer, Combining uncertainty with uncertainty to get certainty? Efficiency analysis for regulation purposes. Eur. J. of Operat. Resear., 274(1), 240 (2019)

19. MG. Scudder, J. Herbohn, J. Baynes, Are portable sawmills a financially viable option for economic development in tropical forests? Forest Polic. And Econ., 100, 188 (2019)

20. T. Kliestik, M. Misankova, K. Valaskova, L. Svabova, Bankruptcy prevention: New effort to reflect on legal and social changes, Science and Engineering Ethics 24, 791803 (2018)

21. M. Hudáková, J. Dvorský, Assessing the risks and their sources in dependence on the rate of implementing the risk management process in the SMEs, Equilibrium. Quarterly Journal of Economics and Economic Policy 13, 543-567 (2018)

22. K. Valaskova, T. Kliestik, M. Kovacova, Management of financial risks in Slovak enterprises using regression analysis, Oeconomia Copernicana 9, 105-121 (2018)

23. D. Katalevskiy, Basics of simulation modeling and system analysis in management (Moscow, Moscow University Press, 2011)

24. A. Krizanova, L. Stefanikova, G. Masarova, Key success factors of company's intelligence program. In 8th International Scientific Conference on Business and Management (Vilnius, Lithuania, 85-92, 2014)

25. E. Kicova, M. Nadanyiova, Marketing strategies in bus transport companies and its impact on increasing the competitiveness. In 15th International Scientific Conference on Globalization and its Socio-Economic Consequences (Rajecké Teplice, Slovakia, 292296, 2015)

26. A. Krizanova, The current possition and perspecives of the integrated transport systems in Slovak republic. Eksploatacja i niezawodnosc - maintenance and reliability, 4, 25-27 (2008)

27. W. Sroka, J. Cygler, B. Gajdzik, The Transfer of Knowledge in Intra-Organizational Networks: A Case Study Analysis. Organizacija 47, 1, 24-34 (2014)

28. B. Gajdzik, W. Sroka, Analytic Study of the Capital Restructuring Processes in Metallurgical Enterprises around the World and in Poland. Metalurgija 51, 2, 265-268 (2012) 
29. G. Gandolfi, M. Regalli, M.G. Soana, M.C. Arcuri, Underpricing and long-term performance of IPOs: Evidence from European intermediary-oriented markets, Economics, Management, and Financial Markets 13, 11-36 (2018)

30. E. Ainsworth-Rowen, Networked, smart, and responsive devices in sustainable internetof-things-based manufacturing systems: Industrial value creation, cognitive decisionmaking algorithms, and operational performance improvement, Economics, Management, and Financial Markets 14, 9-15 (2019) 